\title{
Challenge Me, Disagree with Me: Why Gendered Perceptions to Student Stories of Motivation Enhance Creative Approaches in Engineering
}

\section{Prof. Mona Eskandari, University of California, Riverside}

Mona Eskandari is an assistant professor in the department of mechanical engineering at UC-Riverside, specializing in biomechanics. Prior to joining UCR, she was a researcher at UC-Berkeley and received her doctorate from Stanford University. She was named a University of California Provost's Engineering Research Faculty Fellow, a National Science Foundation Graduate Research Fellow, a DARE Doctoral Fellow, and a Stanford Graduate Science and Engineering Fellow. Eskandari is a recipient of ASEE's Early Engineering Educator Award and the prestigious K. Patricia Cross Future Leaders of Higher Education Award from the Association of American Colleges and Universities.

\section{Dr. Ville Mikael Taajamaa, City of Espoo}

Dr.Ville M. Taajamaa, research and teaching focuses on new product development and engineering education especially in the context of sustainable development. The main focus in his research is the creation of new models and metrics for entrepreneurial, innovative and interdisciplinary engineering education where emphasis is more in the first phases of the engineering process when the problem space is spanned in order to find feasible, viable, credible and desirable solutions.

\section{Dr. Barbara A. Karanian A., Stanford University}

Barbara A. Karanian, Ph.D. , Lecturer, formerly visiting Professor, in the School of Engineering, in the Mechanical Engineering Design Group at Stanford University. Barbara's research focuses on four areas: 1)grounding a blend of theories from social-cognitive psychology, engineering design, and art to show how cognition affects design; 2) changing the way people understand the emotion behind their work; 3) shifting norms of leaders involved in entrepreneurial-minded action; and 4) developing teaching methods with a storytelling focus in engineering and science education. Founder of the Design Entrepreneuring Studio: Barbara helps teams generate creative environments. Companies that she has worked with renew their commitment to expanding paths from creativity to innovation. She also helps individuals answer challenging questions when she teaches some of her methods to engineering, design, business, medicine, and law students. Barbara sometimes uses her storytelling methods as a form, and storytelling as rapid prototyping to help student and industry leaders traverse across the iterative stages of a project- from the early, inspirational stages to delivery. Barbara also uses story as a projective prompt in her experiments. 


\section{Challenge Me, Disagree with Me: Why Gendered Perceptions to Student Stories of Motivation Enhance Creative Approaches in Engineering}

What if your motivation is characterized in ways that do not align with your vision of yourself? Social psychology and engineering education studies have demonstrated that perceptions are important, and frequent, part of everyday interactions and relatability in the classroom and in the workforce. Expectations matter when engineering students tell stories about a colleague's choice to step away from their $\mathrm{CEO}$ /founder position. How might stories featuring negative consequences enhance or interfere with creative approaches in engineering? The purpose of this study is to further extract and investigate the results of work in which participants responded to the role of emotions, expectations, and motivation in the storyline prompt of the engineer/founder who decided to step down as CEO. Two measures are employed: validated coding of the projective storytelling and collected reports of the mood scale (PANAS). Gendered perceptions are examined; men were more negative about themselves and others; and women's stories about women were the only stories with themes of bias, harassment or sexual tension. Do men and women consider it ill-advised for women to discard the power/wealth earned from being innovative? Discussion of a new graduate's entrepreneurial action is crucial for expanding paths from creativity to innovation in engineering education.

\section{Introduction}

Our characterization of others often rivals reality. We tend to express our expectations of individuals in entrepreneurial action with contentment, anger, frustration, confusion, and gratitude in different ways. In seeing how men and women respond to a $\mathrm{CEO} /$ founder's behavior, we discover how interpersonal perceptions matter. Recent engineering graduates tell us that they learn about themselves by observing and listening to all sides of the story, and then they fill in the blanks. One student, after interning as an innovation development lead explains, "I see conflicts that I would never had expected to arise among co-workers, and some internal conflicts in my attempt to reconcile the rulebook and my own conscience. I struggle with people I work with in ways that may harm our relationship but leave all parties in better positions to be creative and better humans moving forward."

The quest for understanding founders success leading innovative companies has inspired research on everything from how VC's make investment decisions [47] to multiple generations coexisting in the same workforce [48] to factors of motivation and emotions [9]. Not surprisingly, the literature suggests that the very best founders are leaders that don't lose sight of their individual storylines while working at the forefront of their markets to maintain their lead in disrupting domains [52]. At the same time, the very best leaders are keeping a reflective eye on what matters to the markets they hope to serve. More important than markets are the people - and their motivation- that comprise those markets. The focus of the current research is not on the corresponding impact that those people have on the potential success of the technology in question, rather it is on the engineer/founder - their motivation or need to perform (achievement) and their emotions (feelings) that impact innovative action.

The reasons for motivation and emotional effects of gender on creative approaches remain unclear. Will a pattern of gendered perceptions of challenge and disagreement spark creative individual solutions and innovation? Multiple studies suggest that innovation occurs in organizations and the classroom $[1,2]$ when there is psychological safety and opportunity for indi- 
vidual and team creativity. Previous studies draw on socio-cognitive and organizational culture perspectives suggesting that gender status conflict impede creativity. Findings indicate that the relationship between creativity and implementation is moderated by gender: women's ideas are not implemented to the same degree as men's [2]. Little study, however, suggests that gender conflict may in fact enhance opportunity for creative approaches. The current paper discusses relevant findings in one experiment with applications to faculty, engineering students, and new graduates as founders and leaders.

To make innovations happen, diverse and interdisciplinary teams and surroundings are required $[3,4]$. However, it all begins in the individual. Emotions that create friction and boundaries are as important as motivation that enable creative, constructive, and proactive practice or emotions. In practice, young graduate engineers who want to create the future instead of staying in a comfortable and predictable world of natural sciences, need to navigate and negotiate their way in complex and constantly changing environments that have both natural sciences based and more human centered challenges. Engineering education research has widely acknowledged this and it is a common baseline for curricula and teaching methods in design and in engineering education yet pragmatic solutions tend to be context driven and focused on areas that are measurable quantitatively. There is a need for facilitated understanding of motivation and emotions. This is especially important during and after the devastating global circumstances of winter and spring 2020. Rules for innovation such as capability to trust and to be trusted, experiment and iterate together, break rules and dream, err, fail and persist, open doors and listen, and pay it forward are all emotion driven instead of being based on actual engineering skills or knowledge [4]. This study aims to shed light on the gap between identified need by men and women for innovation and how to actually achieve it in engineering education $[5,6,7,8]$.

Two organizing questions direct the focus of this study:

1) How does gender influence motivation and emotions in the story of a CEO stepping down from their own startup?

2) In what ways will an individual's expectations of negative consequences contribute to an engineering student's innovation and leadership mindset?

\section{Method}

\section{Participants}

All methodology described here is based on the co-authors' previous 2019 work [9]. Data collection took place in three different university settings mainly due to the availability of college students enrolled in engineering classes: at a private west coast college in the US, a private east coast college in the US, and a university in Finland. Of the eighty-three student enrolled in the 3 classes in 3 different institutions that volunteered to participate, the current analysis is based on seventy-two participants. Participants responses were discarded from the study if their data responses were incomplete. Participants were students studying at the three universities (self-identified male or female in the age range of 18-30). None of the participants were students in any of the co-author's classes. No identifying demographic data exists for any participant.

\section{Measures}

In the preliminary experiment, we gathered story responses and emotion scale reports of the 72 participants to examine findings in the motivation and emotions ascribed to a founder who decided to step down from their position and depart their founded company. This analysis 
presents two dimensions as measures for an experimental exploration of emotion and motivation. First, participants respond to a projective prompt with a story. Then, they respond to a validated short version emotion scale. The experiment included two independent variables (gender cue prompt and gender of participant) and studied effects of these elements on both story-oriented dependent variables and emotion scale reports for the characterization of the engineer as Founder/CEO.

The outcomes were for four conditions when crossing the genders of the participants and story cue: female participant - female cue, female participant - male cue, male participant female cue, and male participant - male cue. A univariate $2 \times 2$ factor ANOVA was used to compare the conditions with $\mathrm{p}<0.05$ set as significant.

The Story (projective prompt as a storyline): Jessica/Peter (Janna/Petteri) graduated at the top of her/his engineering class from university and founded a start-up. Six months later, the company was valued at millions of dollars. She/he decided to step down from her/his position as $C E O$ and take an entry level engineering job in a large company.

\section{Projective Picture Test Prompt: Cue Storyline}

The first instrument, the cue story, is a picture test prompt, inspired by the concept of projection within the Thematic Apperception Test (TAT) [10] and Mattina Horner's original research $[11,12]$. Projection is a defense mechanism referring to when one unknowingly disowns individual characteristics or strong emotions by attributing them to another person. Projection is a crucial component of the picture test methodology. This is the very same methodology that is also featured as a measure in applied psychology and entrepreneurial leader research $[17,22,23,28]$. The storytelling cue methodology comes from the 1943 TAT originally designed by Murray to diagnostically categorize unconscious images with a picture test $[10,14,15]$. Notably, the TAT has been demonstrated as a valuable method for capturing underlying motives [10]. Applications for the workplace began when Atkinson [13] successfully used it to measure achievement motives. More recently, the TAT has been acclaimed for validly testing compatibility and employee-workplace fit, productivity and leadership in the workplace $[18,20]$.

The "cue storytelling line" prompt offers interpretations of actions, styles, narrative expressions, and symbols that provide useful data. Analysis of the story results is on events and forces emerging from the primary character and the setting. Images and themes in the participants' responses become a tool in uncovering hidden interpersonal perceptions not typically found in other, more quantitative research tools. Debate exists concerning whether the measure reflects how individuals perceive themselves, how they perceive others, how they actually behave, norms, stereotypes, bias or some combination of these possibilities, yet experts agree that the TAT is capable of capturing images not likely to be expressed with other techniques [10].

\section{Emotion Scale (PANAS): Mood Report}

The second measure, supplementing the story results, is a short version of the PANAS multiple-item, two factor scale that ensures content validity for assessing the construct of mood. Reports for positive affect (PA) and negative affect (NA) [50]: high PA is a state of high energy and pleasurable engagement whereas low PA is characterized by sadness and lethargy. In contrast, NA is a dimension of distress and un-pleasurable engagement and reflects the extent to which a person feels enthusiastic, active, and alert. NA refers to a variety of aversive mood states like anger, disgust, fear, and anxiety (low NA is a state of calm and serenity) 
[50]. One of the major tasks of the current analysis is to uncover the emotional state that the participants in the experiment ascribe to a founder deciding to depart from their position and take an entry-level engineering job. A Likert scale provides a way for participants to review a number of words that define different feelings as emotions [50] and indicate to what extent the person in the story-cue, Jessica or Peter, feels pleasurable or un-pleasurable engagement. To diminish the effects of the demand characteristic of participants mood during the experiment while completing the survey, participants were also given temporal instructions: to ascribe feeling state for Jessica or Peter at three points in time (moment, post-graduation, and years earlier).

Both measures used in the experiment: the projective-prompt story approach and the mood report draws heavily from theory in applied social-cognitive psychology, leadership, and psychoanalytic theory. The analysis in this paper also uses engineering design principles to consider implications for a new definition of leadership mindset enveloped in the phenomena of innovation. Responses were coded for presence or absence of the following themes and imagery. Table 1 features story examples for coded elements:

Achievement Motivation: depicting the need to strive for personal achievements [13], diligent in work effort and high performance, setting goals and objectives for success and milestones for creative construction $[14,15,16]$.

Innovation: includes themes and images that represents intrigue regarding the generation of new approaches [20,21,22]. Naturally, there exists overlaps in achievement motivation and innovation given visionaries often gain from a sense of excelling; however, innovators are comfortable in dealing with ambiguity and are capable of facing uncertainty while exhibiting creative competence [24].

Affiliation Motivation: measures the degree to which the individual shares the perspective of another and feels capable of stepping in their shoes to better understand their emotional state $[13,14,15]$

Power Motivation: refers to the extent to which a participant has the desire to influence and control $(19,23)$. Power themes may appear to be about work as a win or lose competition. Negative Consequences: themes and images of stress, worry, or bad outcomes for the engineer/leader/founder or the anticipation of negative consequences or denial of success. Danger: refers to themes of violence, intent to harm, or other maladaptive outcomes.

\section{Procedure}

Participants were surveyed in the three different group settings, using a procedure that involved two parts. First, participants were presented with a printed, stapled survey. Each participant received one prompt (for a single gender cue: Jessica or Peter) and since the pages looked exactly the same, participants were unaware of different prompts. Participation was voluntary and participants were given an opportunity to change their mind about completing the survey. The directions were written on the first page (modified from [11, 12]):

"We are interested in your response to the scenario. Thank-you in advance for following the directions below on page one and page two. This won't take more than ten-fifteen minutes of your time." "Imagine that you can tell a story about Jessica. Write this down. Include a beginning, middle, and end."

Jessica graduated at the top of her engineering class from university and founded a start-up. Six months later, the company was valued at millions of dollars. She decided to step down from her position as CEO and take an entry level engineering job in a large company 
The second prompt for mood was:

"The below scale consists of a number of words that describe different feelings and emotions. Indicate to what extent the person in your story feels a particular way at three points in time (moment, post-graduation, years earlier). Use the following scale to record your answers. Read each word and then mark the appropriate number (1, 2, 3, 4, or 5) in the space next to that word."

\section{Results}

\section{Findings regarding Acheivement and Affiliation}

Achievement story themes and images written by female participants included, "Jessica was a quiet genius; I was in classes with her and saw her ability... She solved the problems before anyone else," and male participants remarked, "Peter was driven by his love of engineering." These responses signal both male and female participants writing stories of greater achievement for the female and male CEO respectively.

Affiliation story themes similarly echo participants shared perspectives with the gender of the CEO. Notably, both participant genders wrote nearly twice as many themes of affiliation for their same gendered CEO than otherwise. Empathy images emerged as a common theme with comments such as "She decided the money didn't matter and gave it to charity," and "He took an entry level job in a MedTech company and finally felt like he was doing something that would help others." Stories revolved around granting the CEO a life purpose, depicting them as being helpful, relatable, or caring.

While these findings were not statistically significant (Figure 1), they indicate a trend that does not extend to participant's storyline notions of power and innovation (Figure 1 results adapted from co-authors 2019 experiment) [9].

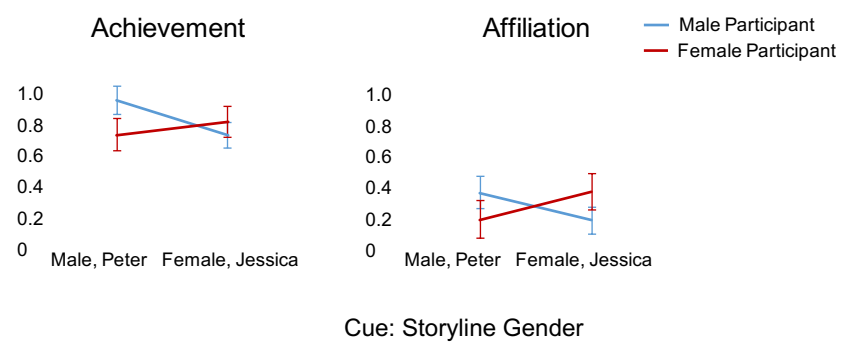

Figure 1 Story Themes: Achievement $(p=0.110)$ and Affiliation $(p=0.101)$. Male and Female Participant responses to Male and Female Story Cue.

Findings regarding Negative Consequences and Danger

Significant differences demonstrated negativity in story themes (Figure 2) were found for participant gender $(\mathrm{p}=0.016)$. Male participants were found to be far more negative overall, inclusive of both male and female CEO, while still more negative towards their own gender. Similarly, female participants criticized the female founder to a greater extent, however, were much less critical overall. In contrast, female participants significantly depicted no danger component for neither the male nor the female CEO (no stories exhibited danger at all) $(p=0.036)$; male participants again imagined more danger to their own gender than to the female CEO. Male participants imagine the female CEO quit before she got fired. Often male participants describe external factors at play in the female CEO's departure, committed to family and requiring self-care that her role was not conducive to (Table 2). 


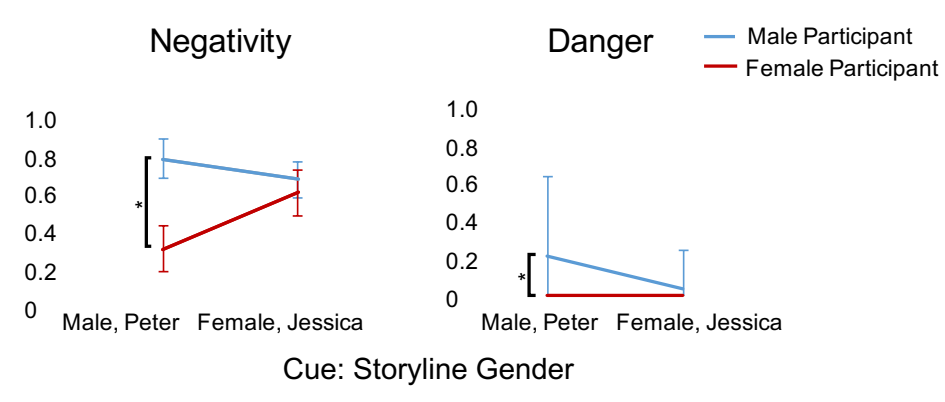

Figure 2 Story themes: Negative Consequences $\left({ }^{*} p=0.016\right)$ and Danger $\left({ }^{*} p=0.036\right)$. Male participants responses more negative overall and negative to Female Story Cue.

Findings regarding Innovation and Power

Regardless of participant gender, all perceive male CEO's to be more innovative (Figure 3). Interestingly, innovation images seemed tied to the decision to step down, finding lack of fulfilment in the job: "He liked creating something new and that was no longer the case as CEO."

In the case of power, female participants appear to uniformly perceive both male and female CEOs while male participants view the female CEO as more powerful.

Participants perception of own gender is mirrored in their perception of CEO gender except for in the case of power and innovation. Male participants score male CEO higher in Achievement and Affiliation (Figure 1), Negativity and Danger (Figure 2), and Innovation (Figure 3), but this reflection does not hold for Power. Similarly, female participants score the female CEO higher in Achievement and Affiliation (Figure 1), and Negativity (Figure 2), yet find the male CEO more innovative (Figure 3). Noteworthy, the gendered perceptions flip for male participants perception of the Power of a male CEO, and a female participant's perception of the Innovation of a female CEO (Figure 3).

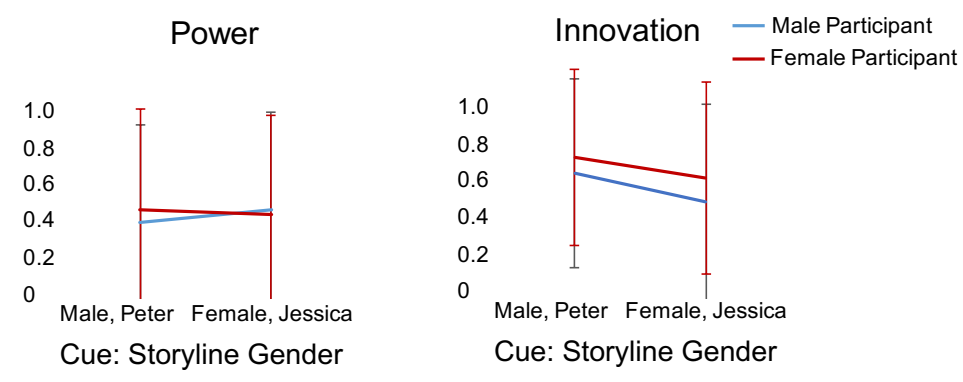

Figure 3 Story Themes: Power $(p=0.858)$ and Innovation $(p=0.368)$. Male and Female Participant responses to Male and Female Story Cue. 
TABLE 1. Stories Exemplifying Six Coded Elements [9].

\begin{tabular}{|l|l|}
\hline CODED & $\begin{array}{l}\text { STORYLINE THEMES } \\
\text { Jessica or Peter }\end{array}$ \\
\hline Achievement & $\begin{array}{l}\text { "Jessica always strived for excellence," "I knew she was a genius," } \\
\text { "Peter was always great at math and science" "He had been a hard } \\
\text { worker with goals since high school." "She was a quiet genius in } \\
\text { class." } \\
\text { "She now saw her friends as only co-workers;" "Peter had no time } \\
\text { for family." }\end{array}$ \\
\hline $\begin{array}{l}\text { Innovation/ In- } \\
\text { novation Self Ef- } \\
\text { ficacy }\end{array}$ & $\begin{array}{l}\text { "Jessica co-created the product," "She was not a typical girl," "Peter } \\
\text { designed a one of a kind bike," "The more he realized what CEO } \\
\text { meant he could no longer express his creativity." }\end{array}$ \\
\hline $\begin{array}{l}\text { Negative Conse- } \\
\text { quences }\end{array}$ & $\begin{array}{l}\text { "Jessica had no interest in running a company." "Peter wanted to } \\
\text { leave being in charge of a company behind him." } \\
\text { "She ruined the product," "He knew he would end up hurting his } \\
\text { company's creation," "He just left and didn't tell anyone why, } \\
\text { "Stress, stress, and more stress." }\end{array}$ \\
Danger & $\begin{array}{l}\text { "He couldn't take it anymore and thought of ending his life." } \\
\text { "He contemplated suicide but figured a way out." }\end{array}$ \\
\hline
\end{tabular}

TABLE 2. Negative Consequences in Stories [9].

\section{Negative Consequences Sentences from Stories for Each Condition}

Male to Male Cue "He is offered a sell-out if and only if he resigns," "He was doing less and less what he loved, was unhappy," "His company flourished but he did not and couldn't handle the stress of being CEO," "He couldn't take the stress anymore," "He knew if he stayed he would ruin the company's creation." "... stuff toppled onto Peter and he went into a coma-2 weeks later he had no recollection of his engineering background or wealth, so he applied for a crappy position, left, and was never heard from again," "He was unsatisfied with all that neither money or computer code could fill," "The stress was too much and the people annoyed him," "Then as an entry level engineer he got fired due to budget cuts," "Despite his initial success, the tedious process began to wear on Peter, and he decided to move to a new endeavor where he could be part of an engineering team again."

Male to Female Cue "Jessica started stealing from the company and not paying the employees," "She found the people tough to work with and couldn't take it anymore," "Jessica was overwhelmed with her situation, wasn't ready for the responsibility and left," "One day Jessica was working on a large project and she realized she had no idea what she was doing, her education didn't prepare her," "She was burned out and the doctors told her if she didn't slow down it would destroy her," "The stress was too much for her," "It wasn't her, she was only successful because of her team," "She was in no position to run a company," "She just quit," "She dropped a bucket of precious materials and they all broke, so they fired her," "She felt like she was at the worst point of her life, her best 
friend Sue and co-founder no longer had the same values, so she walked away," "She quit because she knew she was getting fired."

Female to Female Cue: "She realized what she once realized as true happiness had changed, many thought she was crazy, but she had to leave because it was the only way to restart," "She wanted a simpler task, being a CEO was more of tough task than a passion," "She didn't like getting all the attention, so she stayed quiet and left," "She was tired of putting up with the harassment that was common in the male dominated culture," "The bias got to her," "Those who were friends were now just co-workers ignoring her," "She ran into issues and sexual tensions that distracted her from her work."

Female to Male Cue: "He had to leave because he didn't have the communication skills," "As an entry level engineer, he could observe their CEO to see what he was doing wrong," "Peter didn't like the stress and the amount of worry," "He didn't feel bad in the beginning, but then he realized that there was nothing more he could do and had to leave," "He found himself feeling something was missing in his life, and felt disconnected from (friends) life."

Mood on a Low to High scale of Positive and Negative Affect

The emotion scale measure show that male participants perceive the female with more negative affect (NA) than their reports on male NA or for when females reported on the female. Results reveal that males did not mirror this perception of un-pleasurable engagement with feelings like nervousness, anger, and disappointment to their own gender (Figure 4). In fact, males showed the opposite for the male in the story. The feeling report of significant NA supplements the story results of males as more negative about female founder. Mood results (Figure 4) are adapted from [30].

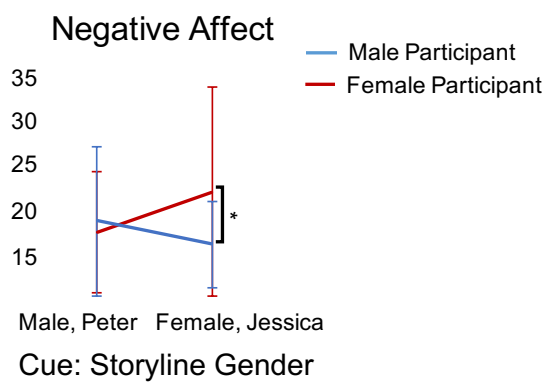

Figure 4: Negative Affect in the Moment Time period vs. Subject Gender for both genders with standard error bars. Male participants scored higher on Negative Affect in the Moment than female participants when writing about females $(\mathrm{p}<0.05)$ whereas there was no significant difference in NA when writing about the males. Adapted from [30].

\section{Discussion}

We sought to consider how motivation and mood differ in storyline themes regarding how an engineer/founder chose to depart from their CEO position in their lucrative startup. Dependent concepts of Achievement, Affiliation, Negativity, Danger, Power, and Innovation revealed notable considerations and interactions. Self-identifying with the founder's actions was a pervasive theme, particularly in regards to high performance (achievement) and relatability (affiliation). However, significant gendered results surfaced in regards to negativity and danger. Male participants were overly critical of their own gender and women. Our findings also link perceptions about the choice to step down from CEO/Founder position with achievement and affiliation, phenomena that are usually considered to be distinct $[15,26,27]$. 
Other results suggest both genders see the Male CEO as more innovative than the Female $\mathrm{CEO}$ indicating an interpersonal difference in perceived value.

Perhaps the most important connection between perceived value and whether someone decides to step down from their position consists of the gender impact on emotional factors for the recently graduated engineer. Despite development of the literature on leadership, gender, status, and conflict, the reasons for motivation and emotional effects of gender on creativity remain unclear. Multiple studies suggest that innovation occurs in organizations and the classroom [1,2]. Analysis of the experiment will enhance awareness of a young engineer's need to perform, definition of what it means to make a commitment to a job position and potentially cope with friction to find creative approaches, and formulate new strategies to innovate. Findings offer strategies for assessing and evaluating curriculum [28, 29] to better understand students' interpersonal attitudes and the relational quality of gendered expectations.

Men and women college students dare to lead with emotion when they tell stories of contentment, anger, frustration, stress, confusion, anxiety and gratitude about the engineer who decided to step down as CEO. Characterizations of the leader are filled with the need to achieve, including images about the challenge to prototype, and create great products in themes of innovation. Obstacles emerge along the way as collision points between needs causing tension, such as the need for achievement colliding with a need for affiliation or innovation. Student stories are brimming with images of negativity when they struggle to find a system for sustainable success. Perhaps most dramatic, stories suggest an assumption of unhappiness with a respondent readiness to rethink their commitment as Founder, or to being CEO and a desire to do something else - something that makes them feel happier like directly designing or doing engineering work, and/or something that allows time for family and friends. Mood data is consistent with low positive affect and a gendered perception of negative affect by men about themselves and the women [30] .

Negative consequences in the focus of many stories about an engineer's choice to step away from the CEO position offers the potential for another lens for analysis. Will unintended consequences be an undesirable outcome? Or, could unintended consequences be a desirable outcome and in fact part of innovation enhancing creativity and creative approaches? Further application from findings as story highlights of motivation, and feeling reports are suggested.

\section{Gendered Expectations}

Each gender appears to have higher expectations of their own gender; this contradicts former notions of women ascribing low expectations to their work to a fear of success [11]. Each gender expected lower of the other gender's success as a CEO and had higher expectations of themselves; this finding deviates from results where women fear success [11], yet it agrees with research on motivation and gender in strongly believing in one's ability [36]. Confirming belief expectations in one's own abilities [31, 32,33] suggests applications for Instructors and for students during classroom experiences. Specific techniques, like storytelling as rapid prototyping, developed by the co-authors [9] for guided discussion are recommended [34]. This is especially useful in classrooms that are male dominated.

It's been many years since women engineers first entered the workforce with goals for excellence in work and aspirations for entrepreneurial leadership. Of course things have changed. Yet, today women lead little more than 3\% of Fortune 500 companies though they make up more than half of the labor force [35]. Additionally, negative stereotypes threaten pervasive 
identifications regarding race and gender with academic work [36]. Perhaps students witness confirming evidence within and beyond the classroom. The concept of stereotype threat [36] informs interpersonal perceptions about the choice to step down from the CEO position. Why would stereotype threat influence college students perceptions about a founder departing early from their founded company? Engineering students and new graduates self-identifying as a minority refer to nuances they observe as implicit bias in the interviewing process during job searches. Perhaps an implicit impression of belonging and experiencing acceptance amplify a need for affiliation (relatedness) shown by women respondents' story images of disappointment or isolation with story themes, "...formerly friends, now only coworkers," or "distracted by sexual tension."

Gendered expectations are not just about one individual's characterization about another, there is an interpersonal and relational component. A recent CNN study [48] reports that it's not only the men showing bias against women, $90 \%$ of men and women, too, are biased against women. Our experiment results indicate both women and men tell stories featuring the male as most innovative. Perhaps, recognizing that both women and men show bias towards women offers a way to recognize the relational component for differences in expectations of leadership and innovation mindset.

\section{Telling Stories of Negativity}

Gender differences are underscored in the results of negativity that features prominently in many stories of the founder/engineer who decides to step down from their CEO position. Also, the mood data showed negative affect indicating low enthusiasm, low activity, worry and evidence of feeling less alert. However, males were the most negative about themselves and women in the stories: "She quit because she knew she would get fired"; "He couldn't take it anymore"; "She dropped a bucket of precious materials... and was fired"; "She was stealing from the company, so they had to fire her." Telling stories of negativity suggest what limits success in perceptions by males about men and women.

\section{Men and Women Expect Negative Consequences Differently}

Also noteworthy, while results reveal that men and women are both distracted as CEO by negative consequences, instead the women appear to be perceived differently than the men when it comes to stepping down from the CEO position. Is it a bigger deal for a man or a woman to leave their position of leadership? Studies have shown that a choice that has financial ramifications [42 ] can be shaped by more situation-sensitive factors, such as emotions [37]. Mood data findings in the experiment affirm men score women with significantly low affect. Low affect includes emotions of disappointment, sadness, anxiety.

Surely employers in the workforce should be aware of how to increase sensitivity for what it means to be innovative among men and women employees [38]. And, faculty have the opportunity to create an environment of support and inclusion in every classroom they teach. The gendered findings in the study indicate that more attention should be paid to women's comments, creations, and innovations in male dominated environments [2]. The co-authors practice methods during classes that inform: direct discussion prompted by methods like sketch a picture, and state memorable moments [39]. A way of understanding the gendered difference in expectations of negative consequences is that there are certain characteristics associated with gender [36]. One outcome unaffected by the male storytelling cue were women's stories about women - the only stories including themes of bias, sexual-distraction, hostility, and harassment. 


\section{Identities Have Consequences}

Members of stereotyped groups often feel extra pressure in situations where their behavior can confirm the negative reputation that their group lacks a valued ability (36). One example of a generational stereotype is a belief by individuals that there is an unwillingness in young professionals and millennials to make a commitment. This offers a potential explanation for a willingness for Jessica or Peter to "step down from the CEO position after six months." We offer an alternative explanation. What if today's new graduates not only rethink, rather they redefine the concept of "commitment?" Personal factors that define the meaning behind making a commitment to a job position is more important than commitment to a specific timeline.

Gender identities also have consequences. One way of understanding this is that there are certain characteristics associated with gender $[36,45]$ protected and not protected by gender. The significant report of interpersonal perceptions of negative affect for Jessica or Peter may be related to higher levels of stress, sadness, lower self-esteem, and even depression [40, 41, 46]. This raises questions about the women and men. Are the women and men equally injured and distracted by the stereotype or identity of running a company? While the current Me Too movement was established with the goal to bring a voice to marginalized people to speak out about gender harassment [43] and shows some evidence of facilitating a culture of transformation for men and women leading it may have caused more confusion than anticipated. Does the current experiment suggest respondents are putting their value of one individual's work above another? Is it likely that the expectation for negative consequences means that college students also expect stress for the CEO/Founder? An expectation of stress might help engineering students and new persons in the workforce creatively cope with internal and external confrontation.

Regardless of the unintended positive consequences of stress, it's not easy to cope with the kind of stress that causes disruption in work routines - different than entrepreneurially maintaining a lead by disrupting domains. Will young engineers enter the workforce with less stress and anxiety if they understand their emotions? If consequences based on feelings about identity are behind a new graduate's capacity for doing innovative work, then being genuine about forces that personally matter will amplify engagement in the workplace (as CEO). Our current paper discussion has some alignment with literature celebrating the hiring and compatibility benefits of those who behaved authentically in interviews and job performance [51].

\section{Unintended Consequences as a desirable part of Innovation}

Unsurprisingly, men and women expect that they will be affected by some undesirable effects of being CEO/Founder and trying to be innovative. They will be challenged. Others will disagree; interpersonal perceptions will be negative. The authors introduce the idea that expectation of and creative coping with negativity or confrontation is a feature that will define the entrepreneurial leader's skill for moving beyond the start-up phase to maintaining growth. In this sense, unintended consequences for engineers as founders may become a desirable part of innovation, showing them as highly perceptive about the paradox of expansion and the resulting conflicts $[39,44]$.

\section{Implications and Limitations}

In the absence of direct data about what really goes on in people's minds when they make assumptions about others, our characterization of the emotions and motivation of others can be 
easily misrepresented. Indeed, one of the limiting outcomes for engineering graduates success in the workforce are the interpersonal perceptions of others for possible innovation bias. In the present study we address this largely subtle finding of bias in gendered perceptions with a projective storytelling cue technique.

Although the present study makes some methodological and possible theoretical advances, it has some important limitations. Perhaps the most important is the nature of the sample of participants. While none of the participants were students in any of the co-author's classes, nor was there any identifying demographic data on any participant, they were enrolled as students in various engineering and design programs, with possible constraints on the generalizability of the results. In this sense, the study has the usual limitations of samples that include college students.

Further research with a modification in the research design might answer questions about gender as a single variable predictor. What if the same set of female respondents were prompted to only write stories with a male CEO in it (female participant with male gender cue prompt)? And, the same set of male respondents could be prompted to only write stories about the female CEO (male participant with female CEO prompt).

The findings shed light on interpersonal perceptions of gender and implicit innovation process of the Founder (individual behind the idea generation to become Founder and implementation as $\mathrm{CEO}$ ). However, implementing ideas also depends on motivation and interpersonal perceptions of negativity that interferes with commitment and follow-through.

Another limitation is that we used only six variables among the many that make-up interpersonal motivation and emotions. Further study design would consider the value or reassessing the specific elements of achievement, affiliation, and innovation. Finally, two measures were used: the mood data from the short version PANAS scale supplementing story findings. Next steps would integrate a more detailed discussion of the meaning of the mood data with the story findings in the discussion.

Since an expectation for negative consequences was such a prominent result in our study and appeared to be an intervening variable, a possible consideration for next steps in research is to create a research design focus with carefully defined negative consequences.

\section{Impact}

It's useful to recognize how our students redefine the concepts of commitment to work and innovation. Faculty should continue to be aware of how to, in addition to facilitating natural sciences driven learning in engineering, increase innovative potential among their students inside and outside of the classroom. We realize it is a tall order for an educator to manage both. One can argue that the bulk of graduate engineers may not need the skills of innovation elaborated in the Introduction of this paper to succeed in engineering work. But if we want engineers who can innovate and create new businesses, natural sciences based knowledge and skills are not enough. Most importantly we need to acknowledge that in addition to a rational worldview that is fundamental in engineering we need a human-centered worldview that is emotion driven. This means understanding gender perceptions as well. Educators are working and teaching in an environment of engineering education that is becoming more and more supportive and inclusive. This is affirming. The engineering design principle of a persona offers a metaphor for understanding impact. How is a persona different from a stereotype? Will a stereotype inform a persona? Applying the similarities and differences of a persona and a 
stereotype has concrete classroom use with potential for amplifying understanding of interpersonal perceptions. The gendered findings in the study indicate there is a relational quality to interpersonal perceptions of gender. Therefore, who and how we pay attention to others is important. The attention that is given to women and men in the classroom, women and men on internships, and women and men in male-dominated work environments is worthwhile.

References

[1] Lee, H., Choi, J., and Kim, S. "Does gender diversity help teams manage status conflict? An evolutionary perspective of status conflict, team psychological safety, and team creativity." Organizational Behavior and Human Decision Processes Vol 144, Jan 2018 pp187199

[2] Foss, L, Woll, K., and Moilenan, M. Creativity and implementation of new ideas; Do organizational structure, work environment and gender matter? International Journal of Gender and Entrepreneurship, 2013.

[3] T. Kelley \& D. Kelley, "Creative Confidence," William Collins, 2013.

[4] V.H.Wang, G.Horowit, "The Rainforest, The Secret to Building the Next Silicon Valley," Regenwald 2012.

[5] E. F. Crawley, J. Malmquist, S. Ostulund, D. R. Brodeur, K. Edstrom, 'Rethinking

Engineering Education,” The CDIO Approach, Second Edition, Springer, 2014.

[6] J. B. Biggs, K. F. Colis, "Evaluating the Quality of Learning the SOLO Taxonomy (Structure of the Observed Learning Outcome).” Academic Press, 1982.

[7] N. Levina, E. Vaast, "Innovating or Doing as Told? Status Differences Overlapping Boundaries in Offshore Collaboration," MIS Quarterly, Vol 32 No. 2, pp 307-332, 2008.

[8] R. M. Ryan and E.L. Deci, "Intrinsic and extrinsic motivations: Classic definitions and new directions," Contemporary Educ Psychology, vol. 25, pp 54- 67, 2000.

[9] Karanian, B., Parlier, A., Taajama, V., Eskandari, M., Provoked Emotion in Student Stories of Motivation Reveal Gendered Perceptions of What it Means to be Innovative in Engineering, ASEE, Tampa, Florida, 2019.

[10]Worchel, F. Aaron L. \& Yates, D.Gender bias on the thematic apperception test. Journal of Personality Assessment. 3, 1990. 593-601.

[11] Horner, M. Toward an Understanding of Achievement-Related Conflicts in Women.

Journal of Social Issues, (28), (2), 1972, pp. 157-175.

[12] Engle, J. "Fear of Success" Revisited: A Replication of Mattina Horner's Study 30 Years Later, American Education Research Association presentation and proceedings, Chicago. Il. 2003.

[13] Atkinson, J. Motives in fantasy, action and society. NJ: Van Nostrand. 1958.

[14] Goodenough, F. . Measurement of Intelligence in Drawings. New York: World Books. 1926 ,

[15] McClelland, D. Human motivation. Van Nostrand: New York. 1987.

[16] McClelland, D. Human motivation. Glenview, Illinois: Scott Foresman. 1984.

[17] Lancor, L. \& Karanian, B. College to Work Transitions: Students Draw Their Futures. In Proceedings of the Frontiers in Education Conference. October, Tempe, Arizona, October, 1999.

[18] McClelland, D. C., \& Boyatzis, R. E. Leadership motive pattern and long-term success in management, Journal of Applied Psychology, 67, 1982, pp 737-743.

[19] McClelland, D., Power: the inner experience. Van Nostrand: New York, 1964.

[20] Schar, M. Chen, H., Sheppard, S. Innovation Self-Efficacy: A Very Brief Measure for Engineering Students. ASEE Proceedings and Conference, Indianapolis, Indiana. June. 2017. 
[21] Smith, K. et al. Connecting and expanding the engineering education research and innovation special session. FIE, Oct. 2011.

[22] Taylor, S. \& Karanian, B. Working Connection: The Relational Art of Leadership. Aesthesis. Vol 2, 2, 2008, pp. 15-22.

[23] Karanian, B. Gender and Leadership: Men and Women's Stories 1995 dissertation.

[24] Kelley, T. \& Kelley D. Creative Confidence: unleashing the creative potential within us All. Crown Business: New York. 2013.

[25] Bandura, A. Self-efficacy: Toward a unifying theory of behavioral change. Psychological Review, 84(2), 1977. pp.191-215.

[26] Cialdini R. et al, 1998. When role salience leads to role rejection: Modest selfpresentation among men and women in two cultures. Personality and Social Psychology Bullentin, 24, 473-481.

[27] Belenky, M. Clinchy, B. Goldberger, N. \& Tarule, J. Women's ways of knowing. New York; Basic Books. 1986.

[28] Duval-Couetil, N., Dyrenfurth, M., Teaching students to be technology innovators: Examininng approaches and identifying competencies. ASEE 2012, San Antonio, TX.

[29] Nelson et al, "Getting there in engineering education. "American Society for Engineering Educaiton, 2017.

[30] Parlier, A., Taajaama, V., Monaghan, G., Karanian, B. Engineering Emotion: Students Tell Stories about the Costs of Being Innovative, FIE, San Jose, California, 2018.

[31] Zhao, H., Seibert, S. E., \& Hills, G. E.. The Mediating Role of Self-Efficacy in the Development of Entrepreneurial Intentions. Journal of Applied Psychology, 90(6) 2005, pp 265.

[32] Leutner, F., Ahmetoglu, G., Akhtar, R., \& Chamorro-Premuzic, T. The relationship between the entrepreneurial personality and the Big Five personality traits. Personality and Individual Differences, 63, 2014. pp 58-63.

[33] Widfield, A,. Eccles, J.S Expectancy-Value theory of achievement motivation. Contemporary Educational Psychology. 25, 2000, pp. 68-81.

[34] Eskandari, M, Karanian, B. et al Open Process for Entrepreneuring Team Collaboration: Parallels from an Academic Researh Team the Start-up They Studied., ASEE, June, 2012.

[35] Women CEO's of the Fortune 1000. New York, NY: Catalyst, 2009.

[36] Steele, C. A Threat in the air: How stereotypes shape intellectual identify and performance. American Psychologist, Vol 52(6), June 1997, 613-29.

[37] Lowenstein, G. F, Weber, E.U., Hsee, C.K. \& Welch, N. Risk as feelings. Psycnological Bulletin, 127, 267-286. 2001.

[38] Eesley, C. and Miller, W. "Impact: Stanford University's Economic Impact via Innovation and Entrepreneurship.” Ewing Marion Kaufman Foundation. 2012.

[39] Karanian, B. Entrepreneurial Leadership: A Balancing Act in Engineering and Science. ASEE Annual Meeting and Conference. 2007.

[40] Kadison, R. DiGeronimo, T. 2006. College of the overwhelmed: the mental health crisis and what to do about it. 2006.

[41] Lythcott-Haims, J. 2015, How to make an adult: break free of the over parenting trap and prepare your kid for success. Henry Holt and Company, New York. 2015, https://www.psychologytoday.com/blog/the-college-shrink/201009/the-number-onecause-college- unhappiness

[42] Carr, F., Steele, C. Stereotype Threat Affects Financial Decision Making, 2010.

[43] E. C. Tippett, The legal implications of the Me Too Movement, heinonline, 2019.

[44] Honig, B., "Entrepreneurship Education: Toward a Model of Contingency-Based Business Planning." Times New Roman Academy of Management Learning \& Education. Vol. 3, 3, 2004, pp. 258-273. 
[45] Correll, S. Constraints into Preferences: Gender, Status, and Emerging Career Aspirations. Vo;. 69 2004, (February: 93-113).

[46] Watson, D. \& Clark, L.\&Tellegen, A. Development and Validation of Brief Measure of Positive and Negative Affect: The PANAS Scales. Journal of Personality and Social Psychology, Vol. 54, No.6. 1988, pp 10063-1070.

[47] Gompers, P., Gormal, W., Kaplan, S., Strebulaev, I. How do venture capitalists make decisions? Journal of Financial Economics, Vol. 135 (1), pp. 169-190, Jan. 2020.

[48] https://www.forbes.com/sites/soulaimagourani/2019/04/25/leading-multiple-generationsin-todays-workforce/\#1 ac229914636

[49] https://www.cnn.com/2020/03/06/us/study-90-percent-bias-against-women-trnd/index.html

[50] Watson, D. \& Clark, L.\&Tellegen, A. Development and Validation of Brief Measure of Positive and Negative Affect: The PANAS Scales. Journal of Personality and Social Psychology, Vol. 54, No.6. 1988, pp 10063-1070.

[51] Gino, F. It pays to be yourself, HBR, January, 2020

[52] Edson, J., Design Like Apple: Seven Principles for Designing Insanely Great Products, Services, and Experiences. New York: Wiley and Sons, 2012. 